\title{
Short-term conversion to open surgery after endovascular stent-grafting of the thoracic aorta: The Talent thoracic registry
}

\author{
Marek P. Ehrlich, MD, ${ }^{\text {a } C h r i s t o p h ~ A . ~ N i e n a b e r, ~ M D, ~}{ }^{\mathrm{b}}$ Hervé Rousseau, MD, ${ }^{\mathrm{c}}$ Jean-Paul Beregi, MD, ${ }^{\mathrm{d}}$ \\ Philippe Piquet, MD, ${ }^{e}$ Marc Schepens, MD, Jean-Michelle Bartoli, MD, ${ }^{g}$ Martin Schillinger, MD, ${ }^{\mathrm{h}}$ and \\ Rossella Fattori, MD ${ }^{i}$
} From the Department of Cardiothoracic Sur-
gery, University of Vienna, ${ }^{\mathrm{a}}$ Vienna, Aus-
tria; Department of Cardiology, University
Hospital Rostock, ${ }^{\text {b }}$ Rostock, Germany; De-
partment of Radiology, Centre Hospitalier
Universitaire, Hopital de Rangueil, ${ }^{\mathrm{c}}$ Tou-
louse, France; Radiologie Vasculaire, Hopi-
tal Cardiologique CHRU de Lille, ${ }^{\mathrm{d}}$ Lille,
France; Centre Hospitalier Universitaire,
Hopital Sainte Marguerite, ${ }^{\mathrm{e}}$ Marseille,
France; Department of Cardiothoracic Sur-
gery, St Antonius Hospital, ${ }^{\mathrm{f}}$ Nieuwagein,
The Netherlands; Centre Hospitalier Univer-
sitaire, Hopital de la Timone, ${ }^{\mathrm{g}}$ Marseille,
France; Department of Internal Medicine,
University of Vienna, ${ }^{\mathrm{h}}$ Austria; and Cardio-
vascular Radiology, University Hospital S.
Orsola, ${ }^{\mathrm{i}}$ Bologna, Italy.

This is a company registry study of the Medtronic Talent thoracic stent-graft. Jean-Paul Beregi reports consulting fees from Cordis and Medtronic, and lecture fees from EV3, Boston Scientific, and Medtronic. Christoph Nienaber reports consulting and lecture fees from Medtronic, Boston Scientific, and Cordis. Rosella Fattori reports consulting fees from Medtronic. Herve Rousseau reports consulting and lecture fees from Medtronic and Gore.

Received for publication May 28, 2007; revisions received Sept 2, 2007; accepted for publication Sept 12, 2007.

Address for reprints: Rossella Fattori, MD, Department of Radiology-Cardiovascular Unit, University Hospital S. Orsola, Via Masseranti 9, 40128 Bologna, Italy (E-mail: rosella.fattori@unibo.it).

J Thorac Cardiovasc Surg 2008;135:1322-6 $0022-5223 / \$ 34.00$

Copyright $(2008$ by The American Association for Thoracic Surgery

doi:10.1016/j.jtcvs.2007.09.036
Objective: Predictors of late conversion to conventional surgery after thoracic endovascular stent-graft placement are currently unknown.

Methods: We analyzed data from 422 of 457 consecutive patients who underwent endovascular thoracic repair with the Medtronic Talent thoracic stent-graft (Medtronic/ AVE, Santa Rosa, Calif). Of these, 16 patients (3.8\%) required late conversion to open surgery during a median follow-up interval of 17 months (range 7-33 months). Six of these patients had undergone previous aortic surgery, 3 patients had previous cardiac surgery, and 5 patients had Marfan syndrome. In patients with late conversion, indications for primary stent-graft placement were dissection in 10 patients, degenerative aneurysm in 5 patients, and penetrating ulcer in 1 patient.

Results: By multivariable Cox analysis, Marfan syndrome (adjusted hazard ratio 9.97, $P=.008$ ), type I endoleak (adjusted hazard ratio $3.99, P=.012$ ), the use of more than 1 stent-graft (adjusted hazard ratio 3.89, $P=.018$ ), and procedural complications (adjusted hazard ratio 17.50, $P=.003$ ) were independent predictors of late conversion.

Conclusion: Endovascular treatment for thoracic aortic disease with the Talent stentgraft is associated with a relatively low rate of late conversion to conventional surgery. Better results may be achieved by excluding patients with Marfan syndrome for such a procedure and early aggressive treatment of early type I endoleaks.

$\mathrm{D}$ escending thoracic aortic aneurysms still represent a potentially life-threatening situation and occur exclusively in this portion of the aorta in $20 \%$ to $30 \%$ of all aneurysm cases. ${ }^{1,2}$ Conventional resection and graft replacement of descending thoracic aortic aneurysms has been the preferred method of treatment but is associated with high morbidity and mortality rates despite improved surgical techniques, intraoperative monitoring of somatosensory-evoked potentials, and spinal fluid drainage. ${ }^{3-6}$ The patient population are usually of older age and present at the time of operation with various comorbidities such as hypertension, obstructive pulmonary disease, and coronary heart disease, all of which have a significant impact on the surgical outcome. Postoperative complications, such as paraplegia and renal and pulmonary insufficiency, contribute to prolonged hospital stays and higher medical cost.

Since the first endovascular stent-graft (ESG) experience in an abdominal aortic aneurysm, ${ }^{7}$ various groups have started to investigate the feasibility of thoracic aortic aneurysmal repair with ESGs. ${ }^{8,9}$ During the last decade, endovascular techniques 


\section{Abbreviation and Acronym \\ $\mathrm{ESG}=$ endovascular stent-graft}

have revolutionized the management of descending thoracic aortic disease, with the benefit of exclusion of the pathologically altered aorta without direct surgical exposure. Although an endovascular technique was initially reserved for patients not suitable for conventional surgery, clinical success led to rapid expansion of indications. ${ }^{10,11}$ Nevertheless, both the potential risk of device failure and the concern about long-term durability remain unresolved issues with this emerging treatment modality. The Talent Thoracic Registry was designed to collect outcome data from patients who underwent endoluminal treatment with the Medtronic Talent thoracic stent-graft (Medtronic/AVE, Santa Rosa, Calif) in 7 European referral centers, and short-term results were reported. ${ }^{12}$ For this article, data collection and analysis were particularly focused on predictors of late conversion to open surgery after thoracic ESG placement.

\section{Materials and Methods Enrollment}

The entire cohort study consisted of 457 consecutive patients who underwent endovascular thoracic aortic repair with the Talent thoracic stent-graft between November of 1996 and March of 2004. Seven European referral centers (Bologna, Toulouse, Rostock, Lille, Vienna, Nieuwegein, and Marseille) provided data from patients treated consecutively, with a minimum of 1-month follow-up. The ethical committee of each institute approved the study. Follow-up analysis was formed on clinical and imaging findings until the last visit date, including all adverse events. Data were collected on case report forms and entered in 2 separate databases by a data-collection specialist and the lead author (R. F.; Maastricht, The Netherlands, and Bologna, Italy). Case report forms were all reviewed by the lead author and checked for inconsistencies. In case of discrepancies, the relevant investigator was queried to ensure appropriate interpretation of events. The 2 different databases were then compared, and errors in data entries were corrected by cross-checking on the specific case report form.

\section{Device Description}

The Talent thoracic stent-graft is composed of Dacron graft fabric supported by self-expanding nitinol springs. The springs are sewn to the graft material with polyester sutures. The graft material is a sheet of monofilament polyester with a seam joining the edges to create a cylindric tube. The connecting bar provides columnar strength to the device and facilitates deployment. All nitinol components are surface treated to enhance long-term fatigue performance. The Talent stent-graft system has many modular sections that can be used to treat a wide variety of thoracic lesions. The stent-graft has 3 proximal and distal configurations. The proximal configurations are FreeFlo, Bare Spring (22 mm only), and Open Web, all of which all have a flared geometry. The FreeFlo design (different from the Bare Spring configuration) has a bare spring and a mini-support spring, which improves sealing for sizes 24 to $46 \mathrm{~mm}$. The distal configurations are Bare Spring, Closed Web, and Open Web. The Open Web configuration was designed for use as distal extensions for the Talent stent-graft system.

\section{Indication for Operation}

The indication for conventional surgery after primary stent-graft placement in these 16 patients was a progressive expansion of the aneurysm in 14 cases and impending rupture in 2 patients.

\section{Operative Technique}

The operative technique was selected according to the localization of the secondary pathology from either endoleaks or other causes in the distal arch or descending aorta. Patients underwent operation by arch replacement via a median sternotomy or distal arch and descending thoracic aorta replacement via a left thoracotomy. Either deep hypothermic circulatory arrest or left heart bypass technique was used. ${ }^{5,13}$ Patients who required deep hypothermic circulatory arrest were cooled to $18^{\circ} \mathrm{C}$, and circulatory arrest was initiated. One patient who experienced an acute retrograde type A dissection 6 months after ESG placement for primary acute type B dissection underwent ascending aorta and a frozen elephant trunk repair through a median sternotomy. ${ }^{14}$ In this patients, antegrade cerebral perfusion was used as an additional brain protection technique. In all 16 patients, the aneurysmal sac was longitudinally opened and any stent-grafts were harvested. Intercostal arteries were not reimplanted in any of the 16 patients. The aneurysm was replaced by a Dacron prosthesis.

\section{Statistical Analysis}

Continuous data are reported as the mean \pm standard deviation or median and total range. Univariate comparisons were done by chisquare tests or Mann-Whitney $U$ tests, as appropriate. Estimates of times to events and the accompanying curves were generated by the method of Kaplan-Meier. Multivariable Cox proportional hazards analysis was applied to determine independent predictors of late conversion adjusting for potential confounders. Baseline variables that were imbalances between patients with and without late conversion by a $P$ value less than .05 were entered into the models. The results of the Cox models are reported as hazard ratios and $95 \%$ confidence intervals. We tested for interactions between baseline variables by multiplicative interaction terms and log likelihood chi-square tests. We assessed the overall model fit using Cox-Snell residuals. Furthermore, we tested the proportional hazard assumption for all covariates using Schoenfeld residuals (overall test) and the scaled Schoenfeld residuals (variable-by-variable testing). According to the tests, the proportional hazards assumption was not violated. Statistical analysis was carried out with SPSS software package version 13.0 (SPSS, Inc, Chicago, Ill).

\section{Results}

Thirty-six of the 457 patients (7.9\%) died within 30 days of the primary stent-graft procedure or within the same hospitalization. Eleven of the deaths were related to the aorta, and the remaining 25 deaths were attributable to other causes, leaving 422 patients $(92.3 \%)$ for this final analysis. A total of 403 of the 422 patients (95\%) had a 3-month follow-up, 
and 368 patients $(87.2 \%)$ had a 6-month follow-up. During the median follow-up time of 17 months (interquartile range 7-33 months), 16 of 421 patients (3.8\%) required late conversion to open surgery after a median interval of 14 months (interquartile range 5-42 months). Baseline demographic and clinical characteristics of patients with and without late conversion are listed in Table 1.

Indication for late conversion to open surgery was the presence of endoleaks in 15 patients ( 7 early, 8 late endoleaks) and a retrograde type A dissection in 1 patient. Univariate predictors for late conversion were previous cardiac surgery $(P=.010)$, maximal aortic diameter $(P=.010)$, Marfan syndrome $(P<.001)$, early type I endoleak $(P=$ $.003)$, and use of more than 1 stent-graft $(P=.016)$. Dissection and acute operation showed a borderline significance $(P=.062$ and $P=.094)$.

Procedural characteristics of the initial stent-graft implantation are listed in Table 2. Patients who underwent late conversion had a larger maximal aortic aneurysmal diameter at the time of the primary stent-graft placement $(77 \mathrm{~mm}$ vs 54 $\mathrm{mm} ; P=.01)$, and several patients in this group needed more than 3 stent-grafts to cover the aneurysmal sac $(P=$ $.01)$. Furthermore, the presence of early endoleak was significantly higher in the late conversion group (43.8\% vs $15.8 \%$; $P=.003$ ).

All but 1 patient survived the complex surgical repair without major complications, resulting in a hospital mortality rate of $6.2 \%$. Fifteen patients underwent operation via a left thoracotomy, and 1 patient required a median sternotomy. Eleven of the 16 patients $(69 \%)$ underwent operation in deep hypothermic circulatory arrest, and the mean circulatory arrest time in this patient group was 39 minutes. One patient required total arch replacement, and 4 patients required partial arch replacement. No neurologic complications were encountered.

By multivariable Cox analysis, Marfan syndrome (adjusted hazard ratio 9.97, $P=.008$ ), type I endoleak (adjusted hazard ratio $3.99, P=.012$ ), the use of more than 1 stentgraft (adjusted hazard ratio 3.89, $P=.018$ ), and procedural complications (adjusted hazard ratio 17.50, $P=.003$ ) were independent predictors of late conversion. The variables age, gender, previous cardiac surgery, maximal aortic diameter, acute operation, and aortic dissection showed no significant association with late conversion (Table 3 ).

\section{Discussion}

This is the first article to report on the late conversion rate to conventional surgery after thoracic ESG placement with the Talent stent-graft. Of the 422 consecutive patients who underwent endovascular thoracic repair and were not lost to follow-up, $16(3.8 \%)$ required late conversion to open surgery after a median interval of 14 months. This rate is much lower than for conversion of abdominal aortic aneurysms as recently reported, with a late conversion rate of $7.9 \% .{ }^{15}$ As
TABLE 1. Baseline demographic data and clinical characteristics of patients with and without late conversion after endovascular treatment of descending thoracic aorta aneurysms

\begin{tabular}{|c|c|c|c|}
\hline & $\begin{array}{l}\text { Patients without } \\
\text { late conversion } \\
\text { ( } n=406,96.2 \%)\end{array}$ & $\begin{array}{l}\text { Patients with } \\
\text { late conversion } \\
\text { ( } n=16,3.8 \% \text { ) }\end{array}$ & $\begin{array}{c}P \\
\text { value }\end{array}$ \\
\hline Male gender (\%) & $309(76.1 \%)$ & $15(93.8 \%)$ & .10 \\
\hline Age (y) & $59(16)$ & $55(17)$ & .20 \\
\hline ASA score & & & .51 \\
\hline ASA & $24(5.9 \%)$ & - & \\
\hline ASA 1 & $37(9.1 \%)$ & $1(6.3 \%)$ & \\
\hline ASA 2 & $125(3088 \%)$ & $3(18.8 \%)$ & \\
\hline ASA 3 & $164(40.4 \%)$ & $9(56.3 \%)$ & \\
\hline ASA 4 & $43(10.6 \%)$ & $3(18.8 \%)$ & \\
\hline ASA 5 & $13(3.2 \%)$ & - & \\
\hline Smoking (SVS score) & & & .35 \\
\hline 0 & $190(53 . q \%)$ & $10(66.7 \%)$ & \\
\hline 1 & $80(22.2 \%)$ & $1(6.7 \%)$ & \\
\hline 2 & $70(19.4 \%)$ & $4(26.7 \%)$ & \\
\hline 3 & $19(5.3 \%)$ & - & \\
\hline $\begin{array}{l}\text { Cardiac comorbidity (SVS } \\
\text { score) }\end{array}$ & & & .051 \\
\hline 0 & $2980(72.4 \%)$ & $9(56.3 \%)$ & \\
\hline 1 & $61(15.08 \%)$ & $5(31.3 \%)$ & \\
\hline 2 & $43(11.1 \%)$ & $1(6.3 \%)$ & \\
\hline 3 & $3(0.88 \%)$ & $1(6.3 \%)$ & \\
\hline $\begin{array}{l}\text { Pulmonary comorbidity } \\
\text { (SVS score) }\end{array}$ & & & .92 \\
\hline 0 & $3600(76.9 \%)$ & $12(75.0 \%)$ & \\
\hline 1 & $55(14.1 \%)$ & $3(18.8 \%)$ & \\
\hline 2 & $29(7.4 \%)$ & $1(6.3 \%)$ & \\
\hline 3 & $6(1.5 \%)$ & - & \\
\hline $\begin{array}{l}\text { Previous aortic } \\
\text { surgery }(\%)\end{array}$ & $89(21.9 \%)$ & $6(37.5 \%)$ & .14 \\
\hline $\begin{array}{l}\text { Previous cardiac } \\
\text { surgery }(\%)\end{array}$ & $18(4.4 \%)$ & $3(18.8 \%)$ & .010 \\
\hline Aneurysm (\%) & $129(31.8 \%)$ & $5(31.3 \%)$ & .97 \\
\hline Dissection (\%) & $159(41.7 \%)$ & $10(62.5 \%)$ & .062 \\
\hline acute & $33(8.1 \%)$ & $2(12.5 \%)$ & \\
\hline chronic & $126(31 \%)$ & $8(50 \%)$ & \\
\hline Penetrating ulcer (\%) & $27(6.7 \%)$ & $1(6.3 \%)$ & .95 \\
\hline Intramural hematoma (\%) & $13(3.2 \%)$ & - & .47 \\
\hline $\begin{array}{l}\text { Traumatic aortic } \\
\text { injury (\%) }\end{array}$ & $87(21.4 \%)$ & - & .038 \\
\hline Marfan syndrome $(\%)$ & $10(2.5 \%)$ & $5(31.3 \%)$ & $<.001$ \\
\hline Acute operation (\%) & $99(24.4 \%)$ & $1(6.3 \%)$ & .094 \\
\hline
\end{tabular}

$A S A$, American Surgical Association; SVS, Society for Vascular Surgery.

in our study, the indication for late conversion was a persistent endoleak.

Transluminal placement of ESGs has been used to treat abdominal aortic aneurysms and descending thoracic aortic pathologies. ${ }^{8}$ Stent-graft repair of the descending thoracic aorta seems to offer a feasible and safe alternative 
TABLE 2. Procedural and postprocedural characteristics of patients with and without late conversion after endovascular treatment of descending aortic aneurysms

\begin{tabular}{|c|c|c|c|}
\hline & $\begin{array}{l}\text { Patients without } \\
\text { late conversion } \\
\text { (n }=406,96.2 \%)\end{array}$ & $\begin{array}{l}\text { Patients with } \\
\text { late conversion } \\
\text { ( } \mathrm{n}=16,3.8 \% \text { ) }\end{array}$ & $\begin{array}{c}P \\
\text { value }\end{array}$ \\
\hline No. of stent-grafts implanted & & & .016 \\
\hline 1 & $289(71.2 \%)$ & $8(50.0 \%)$ & \\
\hline 2 & $87(21.4 \%)$ & $3(18.8 \%)$ & \\
\hline 3 & $26(6.5 \%)$ & $5(31.3 \%)$ & \\
\hline 4 & $2(0.5 \%)$ & - & \\
\hline 5 & $1(0.2 \%)$ & - & \\
\hline 6 & $1(0.2 \%)$ & - & \\
\hline $\begin{array}{l}\text { Maximal aortic } \\
\text { diameter }(\mathrm{mm})\end{array}$ & $54(20)$ & $77(6)$ & .010 \\
\hline $\begin{array}{l}\text { Length of the aortic } \\
\text { neck (mm) }\end{array}$ & $36(34)$ & $46(54)$ & .97 \\
\hline $\begin{array}{l}\text { Cumulative length } \\
\text { of stent-grafts (\%) }\end{array}$ & $126(46)$ & $155(67)$ & .14 \\
\hline $\begin{array}{l}\text { Occlusion of the } \\
\text { subclavian artery (\%) }\end{array}$ & $49(12.1 \%)$ & $2(12.5 \%)$ & .96 \\
\hline Early endoleak (\%) & $78(19.2 \%)$ & $7(43.8 \%)$ & .016 \\
\hline Type 1 & $64(15.8 \%)$ & $7(43.8 \%)$ & .003 \\
\hline Type 2 & $4(1 \%)$ & - & .69 \\
\hline Type 3 & $5(1.2 \%)$ & - & .66 \\
\hline Type 4 & $2(0.5 \%)$ & - & .78 \\
\hline Type 5 & $2(0.5 \%)$ & - & .78 \\
\hline Procedural complications (\%) & $8(2 \%)$ & $2(12.5 \%)$ & .007 \\
\hline Immediate conversion (\%) & $3(0.7 \%)$ & - & .73 \\
\hline Early reintervention (\%) & $8(2.0 \%)$ & $1(6.3 \%)$ & .25 \\
\hline Major complications (\%) & $32(7.9 \%)$ & $1(6.3 \%)$ & .81 \\
\hline Intraoperative death (\%) & - & - & - \\
\hline Additional procedure (\%) & $22(5.4 \%)$ & $1(6.3 \%)$ & .89 \\
\hline
\end{tabular}

compared with conventional repair. ${ }^{16-18}$ Although longterm follow-up is limited, clinical results have been promising. ${ }^{12}$ Stent-graft placement may be of particular benefit, especially in high-risk patients, because this new procedure is easier and less invasive than the conventional surgical approach. ${ }^{19}$ We and others have shown that this method for treating thoracic aortic disease is associated with low early morbidity and mortality rates for patients at high risk and treated on an emergency base, as well as a good long-term outcome. ${ }^{12}$

In addition to the low incidence of late conversions, the morbidity and mortality rate associated with this late conversion to conventional surgery was much lower than other investigators have found in abdominal aneurysms. ${ }^{20,21}$ Only 1 of the 16 patients died after the procedure. The other $15 \mathrm{pa}-$ tients experienced no major postoperative complication and had an uneventful recovery.

By multivariable Cox analysis, Marfan syndrome, procedural complications, type I endoleak, and the use of more than 1 stent-graft were significant predictors of late conver-
TABLE 3. Cox proportional hazards model assessing the risk for late conversion in patients undergoing endovascular repair of descending aortic disease

\begin{tabular}{lccc}
\hline & Hazard ratio & \multicolumn{1}{c}{ 95\% Cl } & P value \\
\hline Age (y) & 1.00 & $0.96-1.04$ & .93 \\
Male gender & 4.25 & $0.55-32.8$ & .17 \\
Previous cardiac surgery & 1.18 & $0.22-6.28$ & .85 \\
Dissection & 1.69 & $0.48-5.96$ & .41 \\
Marfan syndrome & 9.97 & $1.84-54.04$ & .008 \\
Emergency surgery & 4.78 & $0.35-65.30$ & .24 \\
Maximal aortic diameter & 1.03 & $0.98-1.08$ & .31 \\
Type 1 endoleak & 3.99 & $1.35-11.76$ & .012 \\
Use of > 1 stent-graft & 3.89 & $1.26-12.04$ & .018 \\
Procedural complications & 17.50 & $2.70-113.40$ & .003 \\
\hline
\end{tabular}

$\mathrm{Cl}$, Confidence interval.

sion. Procedural complications occurred in 2 patients: The dissection extended into the proximal aorta after stent-graft placement in 1 patient, and the stent-graft dislocated on deployment in 1 patient. Both patients underwent operation conventionally 5 and 6 weeks after the primary procedure. The occurrence of late endoleak formation requiring elective surgical reintervention after stent-graft placement was acceptably low in this study (1.9\%). It was primarily observed after ESG for aortic type B dissection (62.5\%). Late type I endoleaks resulting from chronic enlargement of the proximal or distal landing zone developed in 3 patients. In addition to the progression of the underlying atherosclerotic disease, short proximal or distal landing zones were causative for treatment failure. One of our patients with a type I endoleak exhibited a proximal landing zone of less than $20 \mathrm{~mm}$ in length, although a subclavian to carotid artery transposition was performed before the ESG. The remainder with type $\mathrm{Ib}$ endoleaks showed a critical distal landing zone at the time of implantation, which was characterized by partial thrombus formation at the aortic wall and a critical diameter of $38 \mathrm{~mm}$.

The risk of retrograde aortic dissection after ESG has been reported. ${ }^{14}$ We observed this fatal complication in 1 patient. Injury of the intima by the bare springs of the Talent stentgraft device is suspected to be the cause of this complication. Although this stent-graft-related complication is rare and occurred in only 1 patient in this large series, the development of specially designed stent-grafts for aortic dissection is warranted. The expansion of stent-grafts in the friable tissue of an acute dissected aorta is different than the deployment of ESG in chronic atherosclerotic aneurysms. In atherosclerotic aneurysms, the anchorage of the ESG is dependent on a relatively short proximal and distal landing zone, which necessitates high radial forces generated by the stent. In contrast, ESGs for the treatment of acute dissections have to be designed differently with respect to radial force and flexibility. Because the entire length of the ESG is in contact with the aortic wall, less radial force is sufficient to ensure proper fixation 
of the ESG. Moreover, increased flexibility of the device will reduce the risk for subsequent injury of adjacent aortic tissue.

Most important, the incidence of late conversion after stent-graft placement was significantly high in patients with Marfan syndrome. Five of the 16 patients (31.3\%) who required late open surgery had this connective tissue disease. In light of this remarkable finding, patients with Marfan syndrome should not be treated with endovascular stent-grafts because of their thin, weak, and friable aortic wall that will predispose them to further developing false aneurysm or endoleaks.

Although impressive results and amazing developments have been achieved since the first introduction of ESG in 1991, this technology is still in its infancy. The potential risk of device failure and the concern about long-term durability constitute the major unresolved issues in this emerging treatment modality. Emphasis should be placed on appropriate case selection and the stringency of lifelong surveillance after endovascular therapy, which will further elucidate the indications and limitations of this innovative therapy.

\section{Conclusions}

Endovascular graft repair is not as durable as open repair. However, the rate of late conversion to open surgery was relatively small in this larger series with high success rates. Patients need to be informed of the need for lifelong surveillance and the possible need for secondary procedures before ESG treatment. For patients with Marfan syndrome, EVG repair should currently be performed with extreme caution and restraint.

\section{References}

1. Clouse WD, Hallett JW Jr, Schaff HV, Gayari MM, Ilstrup DM, Melton LJ III. Improved prognosis of thoracic aortic aneurysms: a population-based study. JAMA. 1998;280:12936-9.

2. Bickerstaff LK, Pairolero PC, Hollier LH. Thoracic aortic aneurysms: a population based study. Surgery. 1982;92:1103-8.

3. Hollier LH, Money SR, Naslund TC, Proctor CD Sr, Buhrman WC, Marino RJ, et al. Risk of spinal cord dysfunction in patients undergoing thoracoabdominal aortic replacement. Am J Surg. 1992;164:210-4.

4. Crawford ES, Mizrahi EM, Hess KR, Coselli JS, Safi HJ, Patel VM. The impact of distal aortic perfusion and somatosensory evoked potential monitoring on prevention of paraplegia after aortic aneurysm operation. J Thorac Cardiovasc Surg. 1988;95:357-67.

5. Kouchoukos NT, Wareing TH, Izumoto H, Klausing W, Abboud N. Elective hypothermic cardiopulmonary bypass and circulatory arrest for spinal cord protection during operations on the thoracoabdominal aorta. J Thorac Cardiovasc Surg. 1990;99:659-64.

6. Borst HG, Jurmann M, Buhner B, Laas J. Risk of replacement of descending aorta with a standardized left heart bypass technique. J Thorac Cardiovasc Surg. 1994;107:126-33.

7. Parodi JC, Palmaz JC, Barone HD. Transfemoral intraluminal graft implantation for abdominal aortic aneurysms. Ann Vasc Surg. 1991;5: 491-9.

8. Dake MD, Miller DC, Semba CP, Mitchell RS, Walker PJ, Liddell RP. Transluminal placement of endovascular stent-grafts for the treatment of descending thoracic aortic aneurysms. N Engl J Med. 1994;331:329-34.

9. Inoue KI, Iwase T, Sato M, Yoshida Y, Tanaka T, Kubota Y, et al. Clinical application of transluminal endovascular graft placement for aortic aneurysms. Ann Thorac Surg. 1997;63:522-8.

10. Mitchell RS, Miller DC, Dake MD, Semba CP, Moore KA, Sakai T. Thoracic aortic aneurysm repair with an endovascular stent graft: the first generation. Ann Thorac Surg. 1999;67:1971-4.

11. Mitchell RD, Dake MD, Semba CP, Fogarty TJ, Zarins CK, Liddle RP, et al. Endovascular stent graft repair of thoracic aortic aneurysms. J Thoracic Cardiovasc Surg. 1996;111:1054-9.

12. Fattori R, Nienaber CA, Rousseau H, Beregi JP, Heijmen R, Grabenwoger M, et al; Talent Thoracic Retrospective Registry. Results of endovascular repair of the thoracic aorta with the Talent Thoracic stent graft: the Talent Thoracic Retrospective Registry. J Thorac Cardiovasc Surg. 2006;132:332-9.

13. Fleck T, Hamilton C, Koinig M, Rajek A, Wolner E, Grabenwoger M. Thoracoabdominal aortic aneurysm repair: reducing adverse outcome with left heart bypass, selective visceral perfusion and renal protection. J Cardiothorac Vasc Anesth. 2002;6:287-91.

14. Grabenwoger M, Fleck T, Ehrlich M, Czerny M, Hutschala D, Schoder M, et al. Secondary surgical interventions after endovascular stent-grafting of the thoracic aorta. Eur J Cardiothorac Surg. 2004;26: 608-13.

15. Torsello G, Osada N, Florek HJ, Horsch S, Kortmann H, Luska G, et al. Talent AAA Retrospective Longterm Study Group. Long-term outcome after Talent endograft implantation for aneurysms of the abdominal aorta: a multicenter retrospective study. J Vasc Surg. 2006;43:277-84.

16. Makaroun MS, Dillavou ED, Kee ST, Sicard G, Chaikof E, Bavaria J, et al. Endovascular treatment of thoracic aortic aneurysms: results of the phase II multicenter trial of the GORE TAG thoracic endoprosthesis. $J$ Vasc Surg. 2005;41:1-9.

17. Amabile P, Collart F, Gariboldi V, Rollet G, Batoli JM, Piquet P. Surgical versus endovascular treatment of traumatic thoracic aortic rupture. $J$ Vasc Surg. 2004;40:873-9.

18. Greenberg R, Khwaja J, Haulon S, Fulton G. Aortic dissections: new perspectives and treatment paradigms. Eur J Vasc Endovasc Surg. 2003;26:579-86.

19. Verhoye JP, de Latour B, Heautot JF, Vola M, Langanay T, Corbineau $\mathrm{H}$, et al. Mid-term results of endovascular treatment for descending thoracic aorta diseases in high-surgical risk patients. Ann Vasc Surg. 2006;20:714-22.

20. Vallabhaneni SR, Harris PL. Lessons learnt from the EUROSTAR registry on endovascular repair of abdominal aortic aneurysms repair. Eur J Radiol. 2001;39:34-41.

21. May J, White GH, Harris JP. Techniques for surgical conversion of aortic endoprosthesis. Eur J Vasc Endovasc Surg. 1999;18:284-9. 